\title{
Evaluation of Interfacial Type of Fracture Using Two Adhesive Systems
}

\author{
Abouelleil $\mathbf{H}^{1,2 *}$, Villat $\mathbf{C}^{1,2}$, Attik $\mathbf{N}^{1}$, Grosgogeat $\mathbf{B}^{1,3}$ and Farge $\mathbf{P}^{2}$ \\ ${ }^{1}$ Laboratory of multimaterials and interfaces (CNRS UMR 5615), France \\ ${ }^{2}$ Department of dentistry and endodontics, Faculty of Odontology, Lyon University, France
}

${ }^{3}$ Department of biomaterials, Faculty of Odontology, Lyon University, France

\begin{abstract}
The aim of this study was to concentrate all the loading forces of a bond strength test on the dentin-adhesive interfaces either bonded with an etch-and-rinse or a one-step self-etch adhesive system; the results were compared to that of a glass ionomer cement. Superficial and deep dentin discs were prepared from freshly extracted teeth and bonded to a one with two-step etch-and-rinse Adper ${ }^{\mathrm{TM}}$ Scotchbond ${ }^{\mathrm{TM}}$ 1XT (3M ESPE, Seefeld, Germany), and onestep self-etch Adper ${ }^{\mathrm{TM}}$ Easy Bond (3M ESPE, Seefeld, Germany), and a control group with glass ionmer cement GC Fuji IX (GC Corp, Leuven, Belgium). The 4 by $4 \mathrm{~mm}$ bonded areas were subjected to shear stress and targeted only at the thickened adhesive layer. Bond strength and crack length measurements were obtained. Interface morphology and fracture mechanisms were observed using scanning electron microscopy. Deep and superficial dentin bond strength measurements were statistically significant difference showing higher values for the deep dentin than for the superficial dentin. Crack length measurements for Adper ${ }^{\mathrm{TM}}$ Easy Bond showed a higher value than with Adper ${ }^{\mathrm{TM}}$ Scotchbond, GC Fuji IX. Scanning electron microscopy demonstrated cohesive failures inside the adhesive layer for both adhesive types. The test setup, with the thickened adhesive layer, made the results more dependent on the mechanical properties (stiffness) rather than on the adhesive properties of the adhesive material itself and reflects its ability to resist the fracture load.
\end{abstract}

\section{Keywords: Dentin adhesive; Adhesive testing; Interfacial}

\section{Introduction}

Adhesive restorative dentistry relies on adhesion to tooth structure and depends on the bonding substrate. While bonding to enamel is relatively reliable, adhesion to dentin is much less predictable due to the tubular structure of dentin [1], dentinal fluid transduction and the presence of smear layer [2,3]. In adhesive dentistry, resin monomers replace minerals removed from the intertubular and peritubular dentin after the collagen matrix is expanded after an initial priming of the tissues. Following this interaction by either etch-and-rinse or self-etch components, adhesive resin monomers replace the removed minerals and become micro-mechanically interlocked in the created porosities [1,2].

In order to predict their mechanical properties, dental adhesive systems are submitted to a variety of laboratory tests of their sealing ability by measuring the mechanical bond strength [4].

This is obtained from the load needed to break the bond between dentin and composite; when related to the cross sectional area of the interface, this is referred to as the nominal bond strength $[2,3]$. The failure can be induced through tensile or shear loads; the tests can be achieved either as macro tests (with relatively large bonded areas with bonding surfaces around $7 \mathrm{~mm} 2$ ), or micro tests with smaller bonded areas (with bonding surface around $1 \mathrm{~mm} 2$ ) [2,5-8]. They can be used for the screening of new adhesives in the study of their mechanical properties [7].

Conventional macro-shear tests or tensile tests are easy to perform; micro-shear or micro-tensile tests are more demanding and require a technique-sensitive specimen preparation. A high discrepancy can be found regarding the results of the mechanical bond tests for the same adhesive owing to the laboratories and the tests performed [8]. It is believed that this is explained by the non-uniform interfacial stress distribution $[9,10]$ and the numerous interactions of experimental factors, such as the substrate or methodological factors. Moreover, a wide variation exists in the physical construction of the test with such variables as the geometry of the sample and the physical parameters of the test (knife shape, sample holder geometry, cross head speed) [6-10]. Therefore, the stress build-up and force distribution plays a major part in this variation, and much work has been done to sort out the problem $[9,11,12]$. Finite element and fractographic analysis were used to predict stress distribution across the interface [2]; it was concluded that once dentin cohesive failure takes place, the calculated failure strength no longer represents the interfacial stress [9]. Soft matter physicists [13] calculated that the fracture toughness and the corresponding energy needed for rupture, depends on the type of mechanical test chosen to measure it; therefore the fracture energy strongly depends on the viscoelastic properties of the adhesive, and the velocity of the fracture [9-13].

Several studies have described the relationship between dentin depth and mechanical bond test results. The structural variation of dentin - i.e. depth, number of tubules and the thickness of peritubular layer - affects the obtained bonding values which differ according to the superficial or deep dentin $[14,15]$.

Following these observations an experimental set up was designed to avoid the stress dissipation effects on the mixed physical assembly that comprises the composite and the adhesive. This resulted in a modified type of shear bond testing aimed at the $500 \mu \mathrm{m}$ adhesive layer, without putting stress on the composite part. The adhesive layer was thickened in order to concentrate the load in the adhesive. We investigated the bond strength of dentin-adhesive interfaces either with an etch-and-rinse or a one-step self-etch adhesive system; we used a glass ionomer cement, which has an ionic exchange mechanism of chemical adhesion, as a control. Therefore, the aim of the study was to test the two following hypotheses, when the load is directly applied

*Corresponding author: Hazem Abouelleil, Laboratory of multimaterials and interfaces, 69372 LYON CEDEX 08, France, Tel + 334787786 78; Fax + 334 787786 96; E-mail: hazem.abouelleil-sayed@univ-lyon1.fr

Received January 29, 2014; Accepted February 17, 2014; Published February 19, 2014

Citation: Abouelleil H, Villat C, Attik N, Grosgogeat B, Farge P (2014) Evaluation of Interfacial Type of Fracture Using Two Adhesive Systems. Dentistry 4: 212. doi: $10.4172 / 2161-1122.1000212$

Copyright: @ 2014 Abouelleil H, et al. This is an open-access article distributed under the terms of the Creative Commons Attribution License, which permits unrestricted use, distribution, and reproduction in any medium, provided the original author and source are credited. 
to the adhesive layer: - self-etch and etch-and-rinse adhesives exhibit similar values of adhesion; - superficial and deep dentins do not differ in regards to the adhesion values.

\section{Materials and Methods}

\section{Specimen preparation}

Following removal from patients with informed consent, cariesfree freshly extracted third molars, were kept in a $0.5 \%$-chloramine solution at $4^{\circ} \mathrm{C}$ temperature for five days then in distilled water, until further processing (ISO/TS 11405 norm). After cleaning and removal of superficial debris from the surface, occlusal enamel was removed. Two parallel sections to the occlusal surface were cut to obtain 2 mm-thickness dentin slices. A diamond-disc-operating saw was used at slow speed and under constant irrigation (Isomed, Buehler Ltd, Lake Bluff, IL, USA). The superficial dentin slices were cut below the dentin-enamel junction; the deep dentin sections were made $2 \mathrm{~mm}$ below the first ones, above the roof of the pulp chamber. The obtained dentin slices were then prepared according to the following twosteps procedure: first, the surfaces were mechanically polished using an initial sequence of 120-400-800 grit waterproof abrasive papers of silicon carbide. (Escil, Chassieu, France) Secondly, an additional and final polishing was performed with $6 \mathrm{~mm}, 3 \mathrm{~mm}$ and $1 \mathrm{~mm}$ diamond abrasive papers in order to maximize the removal of the smear layer (Struers A/S, Ballerup, Denmark). At the end of the polishing process, all the specimens were ultrasonically cleaned for $8 \mathrm{~min}$ in water, rinsed thoroughly in ultra-pure water, and finally kept in deionized water at $4^{\circ} \mathrm{C}$ temperature.

Each group consisted of 15 samples prepared one with twostep etch-and-rinse Adper ${ }^{\text {Tx }}$ Scotchbond $^{\text {max }}$ 1XT (3M ESPE, Seefeld, Germany), and one-step self-etch Adper ${ }^{\mathrm{rm}}$ Easy Bond (3M ESPE, Seefeld, Germany), and a control group with glass ionmer cement GC Fuji IX (GC Corp, Leuven, Belgium). For each adhesive two dentin substrates were considered (superficial and deep).

\section{Adhesion area and Adhesive layer thickness control}

In order to minimize the adhesion area variation in bond strength measurements, the adhesive thickness was geometrically constrained; a polysiloxane rubber-base mold with a constant area of (4 X $4 \mathrm{~mm})$ surface was applied under mechanical pressure over each sample of the polished dentin surface.

A constant volume $(9 \mu \mathrm{l})$ was delivered within the mold; this resulted in a $500 \mu \mathrm{m}$ thickness of the adhesive layer on each sample.

\section{Bond strength measurements and crosshead speed}

Bond strength measurements were made using a Universal Mechanical testing machine MTS $^{\text {mu }}$ (Servo hydraulic - Adamel Lhomargy DY-34, France), where a blade was forced perpendicularly to the adhesive interface (Figure 1). Data were recorded with the MTS $^{\text {m }}$ software attached to the machine.

We used a $15^{\circ}$ angle beveled sharp blade with a $15 \mu \mathrm{m}$ cutting edge, so that the load of the blade would target only the thick adhesive layer. A digital stereomicroscope was used to obtain the blade bevel and cutting edge measurements; all experiments were conducted with a low cross head speed at $0.5 \mathrm{~mm} / \mathrm{min}$.

\section{Crack length measurements}

The crack length measurement was calculated as the distance travelled by the blade into the substrate - before separation of the

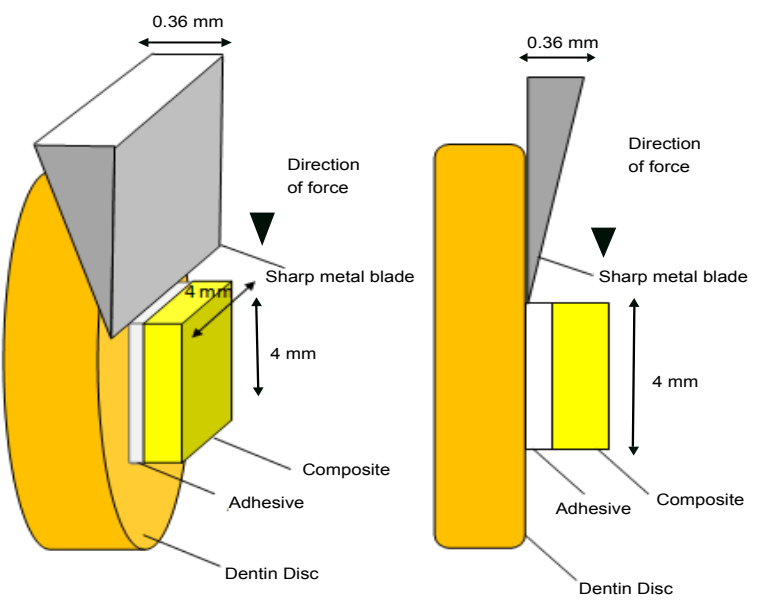

Figure 1: Experimental device set-up.

adhesive from the dentin surface. This was obtained with the data from the Universal Mechanical testing machine $\mathrm{MTS}^{\mathrm{m}}$ when testing the interfacial bond strength.

\section{Scanning electron microscopy}

In order to locate the position of the crack within the specimen, scanning Electron microscope observations (S800-1, Hitachi Europe Ltd. Whitebrook, Berkshire SL6 8YA Parc, United Kingdom) were conducted on randomly selected specimens from each group. Samples were dried, sputter coated with metal and observed. The level of separation was determined for each substrate under magnification. The failure mode was assessed as: adhesive (along the interface without composite or dentin involvement), cohesive (totally in dentin or in composite) or mixed (at the interface involving dentin or/and composite).

\section{Statistical analysis}

Statistical significance of the results was calculated by means of the SPSS ${ }^{\mathrm{Tm}}$ Software version 17.0.2, and the bond strength results and crack length measurements data were analyzed by ANOVA. Multiple comparisons were done using the Fisher's test $(0.001<\mathrm{p}<0.05)$.

\section{Results}

The bond strength values were recorded according to the type of dentin - superficial or deep- for each adhesive. The crack length measurements were obtained from the mechanical testing machine records and plotted to the applied load at the rupture point. No pretest failure occurred among the samples, none of the adhesive discs did prematurely detach in any of the groups.

\section{Bond strength measurements}

The forces needed for debonding were calculated in MPa. The bond strength measurements vary according to the dentin substrate and to the adhesive type. Higher values were noted with the self-etch than with the etch-and-rinse adhesive which appear to exhibit different behaviors.

Bond strength values according to the superficial or deep dentin: Bond strength values according to the dentin substrate depth are presented in figure 2. Deep and superficial dentin bond strength 


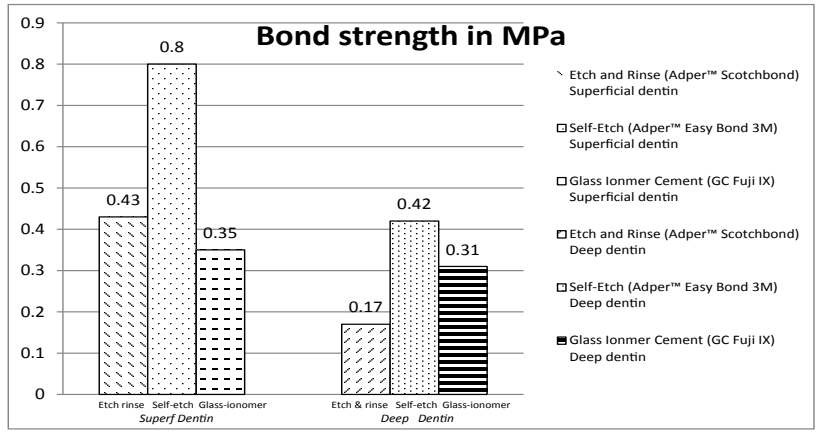

Figure 2: Bond strength values according to type of adhesive used and according to type of dentin substrate.

measurements were respectively at $0.43 \pm 0.27 \mathrm{MPa}$ and $0.17 \pm 0.12$ $\mathrm{MPa}$ for the etch-and-rinse adhesive (Adper ${ }^{\mathrm{rm}}$ Scotchbond), with a mean difference at $0.265 \mathrm{MPa}(p=0.0033)$. They were at $0.8 \pm 0.35 \mathrm{MPa}$ and $0.42 \pm 0.31 \mathrm{MPa}$ with a mean difference at $0.377 \mathrm{MPa}(p<0.0001)$ for the self-etch adhesive (Adper ${ }^{\text {Tix }}$ Easy Bond $\left.3 \mathrm{M}\right)$. There was a statistically significant difference showing higher values for the superficial than for the deep dentin. With the glass ionomer cement (GC Fuji IX) the values were at $0.35 \pm 0.18 \mathrm{MPa}$ and $0.31 \pm 0.14 \mathrm{MPa}$ with a mean difference of $0.032 \mathrm{MPa}(p=0.7228)$; no statistically significant difference was noted between the dentin substrate depths. Statistical relevance of these results is presented in table 1 .

Bond strength values according to the type of adhesive: Bond strength values according to the type of adhesive are presented in figure 2. Considering both dentin substrates superficial and deep dentin, a significant difference was found between etch-and-rinse and selfetch adhesives: for superficial dentin there was a mean difference of $0.363(p<0.0001)$; for the deep dentin there was a mean difference of $0.251(p=0.0060)$ with higher values for the self-etch adhesive. Also, a significant difference was found between the bond strength values of self-etch (Adper ${ }^{\mathrm{m}}$ Easy Bond 3M) and the glass ionomer cement (GC Fuji IX) with the superficial dentin with a mean difference of 0.451 ( $p=0.0001)$, while for the deep dentin there was no significant difference for the bond strength values with a mean difference of 0.106 $(p=0.2387)$. Similarly there was a significant difference between bond strength values of the etch-and-rinse (Adper ${ }^{\text {max }}$ Scotchbond) and the glass-Ionmer Cement (GC Fuji IX) for the superficial dentin (mean difference $0.088, p=0.3262$ ). Statistical relevance of these results is presented in table 1 .

\section{The crack length measurements in $\mathrm{mm}$}

Crack length measurements according to the dentin substrate: The crack length measurements before separation are presented in figure 3. For the self-etch (Adper ${ }^{\mathrm{rm}}$ Easy Bond 3M) there was no significant difference between superficial dentin and deep dentin; the crack length measurements were respectively at $0.69 \pm 0.2 \mathrm{~mm}$ and 0.51 $\pm 0.2 \mathrm{~mm}$ ). The statistical relevance of these results is presented in table 2 .

Crack length measurements according to the adhesive type used: Higher values are noted for self-etch than for etch-and-rinse adhesive. There was a significant difference between self-etch (Adper ${ }^{\text {rw }}$ Easy Bond $3 \mathrm{M})$ and etch-and-rinse (Adper ${ }^{\mathrm{m}}$ Scotchbond) on both superficial dentin (mean difference $0.39-p<0.0001$ ) and deep dentine (mean difference $0.232-p=0.0029$ ). In addition a significant difference was calculated between self-etch (Adper ${ }^{\text {rx }}$ Easy Bond $3 \mathrm{M}$ ) and glass ionomer cement (GC Fuji IX) with a mean difference of $0.36(p<0.0001)$ for superficial dentin and weaker significance for deep dentine with a mean difference of $0.14(p=0.0567)$.

Correlation between load in MPa and the distance travelled by the blade before separation: No correlation was found in figure 4 drawn between the load in $\mathrm{MPa}$ and the distance travelled by the blade before separation for the different adhesive types according to the dentin substrates. The values for deep dentin are organized in a linear fashion; one can possibly conclude that the substrate is homogeneous and that the mechanical behavior is essentially related to the material.

\begin{tabular}{|c|c|c|c|c|}
\hline material & $\begin{array}{l}\text { Etch-and-rinse } \\
\text { (Adper }{ }^{\mathrm{TM}} \\
\text { Scotchbond) }\end{array}$ & $\begin{array}{c}\text { Self-Etch } \\
\text { (Adper }{ }^{\mathrm{TM}} \text { Easy Bond } \\
3 \mathrm{M})\end{array}$ & Fisher & $P$ value \\
\hline Superficial dentin & $0.43(0.27)$ & $0.8(0.35)$ & b & $<0.0001$ \\
\hline Deep dentin & $0.17(0.12)$ & $0.42(0.31)$ & b & 0.006 \\
\hline ANOVA & b & b & & \\
\hline$P$ value & 0.003 & $<0.0001$ & & \\
\hline
\end{tabular}

aMeans are not significantly different (Fisher's test)

bif the $p$-value $<0.05$, the MPa for debonding is significantly different

Table 1: Fisher's test results for Bond strength values of the different adhesive types.

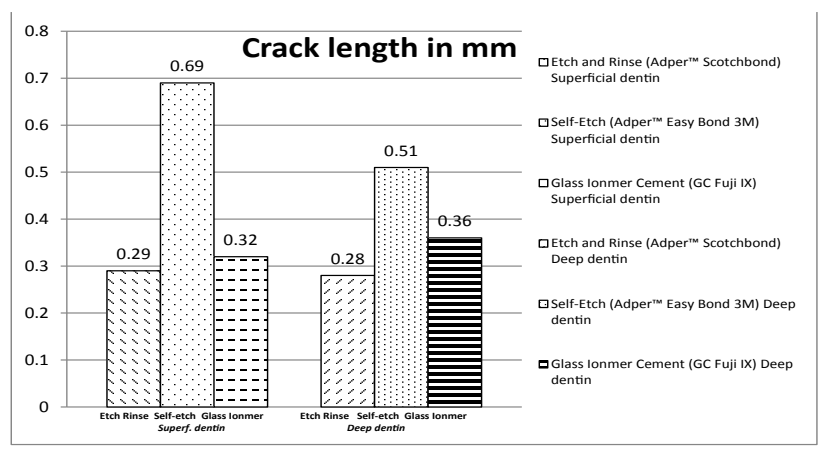

Figure 3: Distance in mm according to type of adhesive used and according to type of dentin substrate.

\begin{tabular}{|c|c|c|c|c|}
\hline material & $\begin{array}{l}\text { Etch-and-rinse } \\
\text { (Adper }{ }^{\mathrm{TM}} \\
\text { Scotchbond) }\end{array}$ & $\begin{array}{c}\text { Self-Etch } \\
\text { (Adper }{ }^{T M} \text { Easy Bond } \\
3 \mathrm{M})\end{array}$ & Fisher & $P$ value \\
\hline Superficial dentin & $0,29(0,1)$ & $0,69(0,2)$ & b & $<0.0001$ \\
\hline Deep dentin & $0,28 \quad(0,1)$ & $0,51(0,2)$ & b & 0.0003 \\
\hline ANOVA & b & b & & \\
\hline$P$ value & 0.83 & 0.0059 & & \\
\hline
\end{tabular}

aMeans are not significantly different (Fisher's test)

bif the $p$-value $<0.05$, the MPa for debonding is significantly different

Table 2: Fisher's test results for crack length measurements of the different adhesive types.

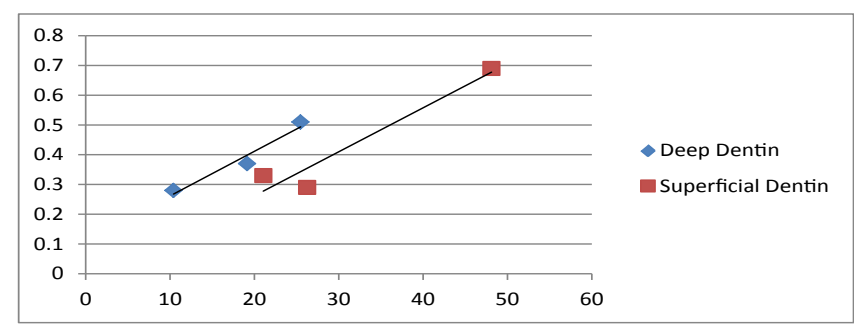

Figure 4: Relationship between load in MPa and distance in $\mathrm{mm}$ for the three adhesive types and the two dentin substrates. 
The values for superficial dentin are more scattered; thus this substrate appears more heterogeneous resulting in larger value dispersion, possibly depending on the material. Moreover, the plotted lines are parallel for both dentin substrates and suggest a linear relation between the load applied and the crack propagation into the material.

Scanning electron microscopy results: Several samples were inspected by scanning electron microscopy to detect the level of separation between the adhesive complex and the dentin disc. The crack was restricted within the adhesive layer, as shown in figures 5 and 6 , resulting in an adhesive failure.

\section{Discussion}

On behalf of the reported results in the present study, both null hypotheses were rejected. Self-etch and etch-and-rinse adhesives did not perform similarly in the experimental physical set-up described here. Higher values were found for self-etch (Adper ${ }^{\text {Tax }}$ Easy Bond 3M) than for etch-and-rinse adhesive (Adper ${ }^{\mathrm{rw}}$ Scotchbond). This was noted for both superficial and deep dentin; in addition the level of significance was increased for superficial dentin which demonstrated higher bond strength values.

In the present experiment, the adhesive bonding area and thickness measures were maintained constant by using a polysiloxane rubber base mold that was applied under pressure, to facilitate the interpretation of the nominal strength values $[16,17]$. Stress concentration at the adhesive interface is a major factor that complicates the interpretation of the nominal bond strength results. The nature of the test set-up further reflects the ambiguity of the results $[9,18]$. The present experimental

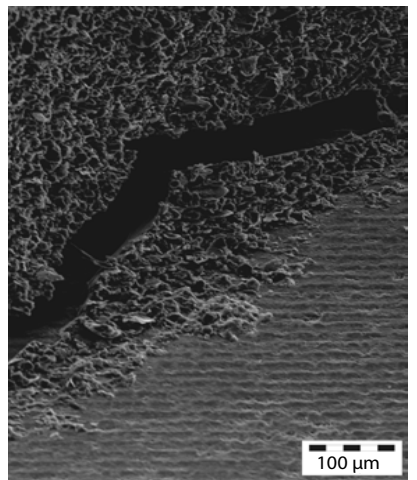

Figure 5: Fracture line (arrow) inside the adhesive layer of the self-etch adhesive.

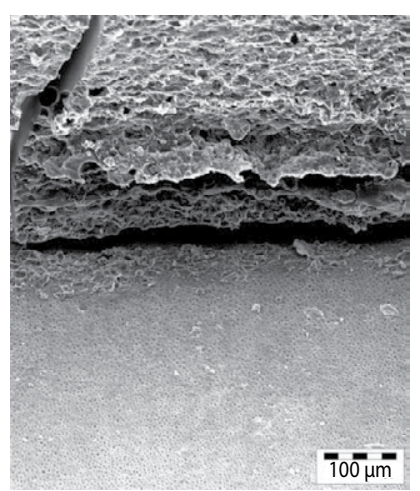

Figure 6: Fracture line inside the adhesive layer of the etch-and-rinse adhesive. set-up tried to address the common problem of stress distribution found with bond strength testing methods. Though the complex stress distribution seems unavoidable, we attempted to enlarge the adhesive layer thickness so that only the layer would be submitted to the main load. Electron microscopic observations images obtained confirmed that the targeted area was solely the adhesive layer, resulting in a failure within the adhesive layer.

The obtained values are comparable to previously reported fracture toughness values [19], by concentrating the load; the set-up tries to propagate a crack in the adhesive joint by using a sharp blade without exerting pressure on other components of the adhesive interface.

The measurements somewhat go against the common knowledge that etch-and-rinse adhesive systems perform better than other classes of adhesives for bond testing [3]. Yet an important difference must be pointed out regarding the method used in the present study, the mechanical properties of the adhesive material itself was the measured element as targeted by the sharp blade tip which endured most of the concentrated force. This is in contrast to the blunt knife used in the shear test method that spreads the load on all components of the adhesive bond complex [10]. We concluded that the material stiffness and its capability to withstand stress before failing were the main factors influencing the results. The comparable results in both the bond strength measurements and the crack measurement length for each material equally support the above conclusion. The force displacement curves obtained for the self-etch showed that distance travelled by the blade into the material before failure significantly exceeded that with the other two materials thus showing a higher flexibility and resilience; the adhesive layer would act as an elastic buffer. The elastic bonding concept, as described by Van Meerbeek [20], could serve as an explanation for the higher bond strength obtained with this material in our study.

The two types of adhesives used in this study appear similar in regards to the monomer composition presented in table 3, with BisGMA and HEMA as the main components, also containing ethanol and water and the presence of silica fillers to increase material strength, while the main difference lies in the presence of acidic monomers in the self-etch adhesive. On the other hand the higher values obtained in this study with the Self-Etch adhesive Adper ${ }^{\text {re }}$ Easy Bond adhesive would be related to the presence of a higher percentage of the more bulky and stiffer monomer Bis-GMA; in addition the dentin surface preparation minimized the presence of the smear layer thus decreasing the bonding strength for this type of adhesive [20].

As expected the glass ionomer cement had low mechanical properties and performances in this strength test; as a self-adhesive material it has good clinical adhesive properties depending on a chemical bonding to tooth structure, but exhibits a weaker performance during in vitro test methods which concentrate stress loading $[18,19]$.

In the present study we found a significant difference between the deep and superficial dentin bond strength measurements. Deep dentine has a lower mineral content, a greater number and area of dentinal tubules, a smaller area of inter-tubular dentine, and is inherently wetter in vivo than superficial dentine; moreover, the critical stress intensity factor in superficial dentin can double that of deep dentin $[14,15]$. Our data compare to previously reported results considering the dentin depths [14].

It is worth noting that the results obtained in this study were associated with quite large standard deviations, it was found that even with fracture toughness which is an intrinsic property, values 


\begin{tabular}{|c|c|c|c|}
\hline & Composition & Batch \# & Manufacturer \\
\hline $\begin{array}{c}\text { Etch-and-rinse } \\
\text { (Adper }{ }^{\mathrm{TM}} \text { Scotchbond) }\end{array}$ & $\begin{array}{l}\text { Bis-GMA } 10-20 \% \\
\text { HEMA 5-15\% } \\
\text { Polyalkenoic acid copolymer } \\
5-10 \% \\
\text { Water } \\
\text { Ethanol } \\
\text { Silica particles } \\
\text { initiators }\end{array}$ & 51010 & $\begin{array}{l}\text { 3M ESPE, } \\
\text { Seefeld, Ger- } \\
\text { many }\end{array}$ \\
\hline $\begin{array}{c}\text { Self-Etch } \\
\text { (Adper }{ }^{\mathrm{TM}} \text { Easy Bond) }\end{array}$ & $\begin{array}{l}\text { Bis-GMA } 15-25 \% \\
\text { HEMA } 15-25 \% \\
\text { functionalised polyalkenoic } \\
\text { acid } \\
\text { Water } \quad 10-15 \% \\
\text { Ethanol } \quad 10-15 \% \\
\text { Silica particles } \\
\text { initiators } \\
\text { methacrylated phosphoric } \\
\text { esters, } \\
1,6 \text { hexanediol dimethacry- } \\
\text { late, methacrylate } 5-10 \%\end{array}$ & 437866 & $\begin{array}{l}\text { 3M ESPE, } \\
\text { Seefeld, Ger- } \\
\text { many }\end{array}$ \\
\hline
\end{tabular}

Other names for Adper ${ }^{\mathrm{TM}}$ Scotchbond: Adper ${ }^{\mathrm{TM}}$ Single Bond Plus (USA) Adper $^{\mathrm{TM}}$ Single Bond 2 (Latin America, Asia, Australia)

Table 3: Composition of the two types of adhesives used

are usually associated with large standard deviations (>25\%) [16]. The elastic property differences across interfaces can lead to high interfacial stresses during interfacial fracture toughness. A wide scatter for individual results in dentin adhesion studies is reported [21] and the coefficients of variation range between 28 and $36 \%$ for shear tests, $21 \%$ and up to $40 \%$ for micro-shear tests [6]. Non-uniform stresses generated within the shear zone have a significant effect on the mode of failure. Finite element analysis showed that complex stress states occur at the interface and resulting in unstable crack propagation [8].

Our study design depended largely on the viscoelastic properties the materials used and their ability to withstand stress rather than the different modes of adhesion. Earlier studies emphasized the importance of material stiffness and its ability to withstand loads and shock during function $[14,20,22]$. It has been suggested that the dentin-composite joint should be reasonably flexible to minimize stress concentrations in the bond during function. A number of factors influence the relative stiffness of this interface zone including the elastic moduli of its individual components, the thickness of these component layers, or the degree of interaction between them. Preliminary studies found a significant positive correlation between relative interfacial stiffness and interfacial fracture toughness through varying the adhesive resin layer thickness and modulus [23]. Previous studies that tested the adhesive layer properties [24] concluded that a flexible adhesive layer could resist polymerization shrinking stress and emphasized the role of adhesive constituents on mechanical properties [25,26].

Our results stress the role of dentin substrate type, and suggest a clinical relevance regarding the type of dentin involved in the cavity design. In vitro adhesion to dentin studies should not consider dentin as a uniform substrate; variations in dentin depth can influence the results of bond strength measurements.

Future work should include a wider variety of adhesives whether self-etch or etch-and-rinse both filled and unfilled. By concentrating the load to the adhesive layer, the soft matter physicist approach will provide quantifiable data, to study the role of chemical constituents in the mechanical properties of adhesives.

\section{Conflict of Interests}

With the submission of this manuscript the authors would like to certify that all of the named authors were involved in the work leading to the publication of the paper and our Institute's representative is fully aware of this submission. And all the named authors have read the paper before its submission; the authors have declared that no competing interests exist.

\section{Acknowledgement}

The authors wish to express their appreciation to Beatrice Burdin, PhD, at the Microstructures Technology Center of University Claude Bernard Lyon 1 for assistance with the SEM study. We also acknowledge 3M ESPE and GC Corp support for providing the adhesives used in this study.

\section{References}

1. Silva e Souza MH Jr, Carneiro KG, Lobato MF, Silva e Souza Pde A, de Góes MF (2010) Adhesive systems: important aspects related to their composition and clinical use. J Appl Oral Sci 18: 207-214

2. De Munck J, Van Landuyt K, Peumans, Poitevin A, Lambrechts P, et al. (2005) A critical review of the durability of adhesion to tooth tissue: methods and results. J Dent Res 84: 118-132.

3. Cardoso MV, de Almeida Neves A, Mine A, Coutinho E, Van Landuyt K, et al. (2011) Current aspects on bonding effectiveness and stability in adhesive dentistry. Aust Dent J 56: 31-44.

4. Bayne SC (2012) Correlation of clinical performance with 'in vitro tests' of restorative dental materials that use polymer-based matrices. Dent Mater 28 $52-71$

5. Roeder L, Pereira PN, Yamamoto T, llie N, Armstrong S, et al. (2011) Spotlight on bond strength testing--unraveling the complexities. Dent Mater 27: 11971203

6. Braga RR, Meira JB, Boaro LC, Xavier TA (2010) Adhesion to tooth structure: a critical review of "macro" test methods. Dent Mater 26: e38-49.

7. Carvalho RM, Manso AP, Geraldeli S, Tay FR, Pashley DH (2012) Durability of bonds and clinical success of adhesive restorations. Dent Mater 28: 72-86.

8. Scherrer SS, Cesar PF, Swain MV (2010) Direct comparison of the bond strength results of the different test methods: a critical literature review. Dent Mater 26: e78-93.

9. Tantbirojn D, Cheng YS, Versluis A, Hodges JS, Douglas WH (2000) Nomina shear or fracture mechanics in the assessment of composite-dentin adhesion? J Dent Res 79: 41-48.

10. Salz U, Bock T (2010) Testing adhesion of direct restoratives to dental hard tissue - a review. J Adhes Dent 12: 343-371.

11. Pashley DH, Sano H, Ciucchi B, Yoshiyama M, Carvalho RM (1995) Adhesion testing of dentin bonding agents: a review. Dent Mater 11: 117-125.

12. Kotousov A, Kahler B, Swain M (2011) Analysis of interfacial fracture in dental restorations. Dent Mater 27: 1094-1101.

13. Léger L, Creton C (2008) Adhesion mechanisms at soft polymer interfaces Philos Transact A Math Phys Eng Sci 366: 1425-1442.

14. Tam LE, Yim D (1997) Effect of dentine depth on the fracture toughness of dentine-composite adhesive interfaces. J Dent 25: 339-346.

15. Villela-Rosa AC, Gonçalves M, Orsi IA, Miani PK (2011) Shear bond strength of self-etch and total-etch bonding systems at different dentin depths. Braz Oral Res 25: 109-115

16. Van Noort R, Cardew GE, Howard IC, Noroozi S (1991) The effect of local interfacial geometry on the measurement of the tensile bond strength to dentin. J Dent Res 70: 889-893.

17. Neves Ade A, Coutinho E, Poitevin A, Van der Sloten J, Van Meerbeek B, et al (2009) Influence of joint component mechanical properties and adhesive laye thickness on stress distribution in micro-tensile bond strength specimens. Dent Mater 25: 4-12.

18. Van Meerbeek B, Peumans M, Poitevin A, Mine A, Van Ende A, et al. (2010) Relationship between bond-strength tests and clinical outcomes. Dent Mater 26: e100-121.

19. Soderholm KJ (2010) Review of the fracture toughness approach. Dent Mater 26: e63-77.

20. Van Meerbeek B, Willems G, Celis JP, Roos JR, Braem M, et al. (1993) Assessment by nano-indentation of the hardness and elasticity of the resindentin bonding area. J Dent Res 72: 1434-1442. 
Citation: Abouelleil H, Villat C, Attik N, Grosgogeat B, Farge P (2014) Evaluation of Interfacial Type of Fracture Using Two Adhesive Systems. Dentistry 4: 212. doi:10.4172/2161-1122.1000212

21. Tam LE, Pilliar RM (2000) The effect of interface stiffness on dentin-composite interfacial fracture resistance. J Dent 28: 487-493.

22. Ausiello P, Apicella A, Davidson CL (2002) Effect of adhesive layer properties on stress distribution in composite restorations--a 3D finite element analysis. Dent Mater 18: 295-303.

23. Eliguzeloglu E, Eraslan O, Omurlu H, Eskitascıoglu G, Belli S (2010) Effect of hybrid layer and thickness on stress distribution of cervical wedge-shaped restorations. Eur J Dent 4: 160-165.
24. Sadr A, Shimada Y, Lu H, Tagami J (2009) The viscoelastic behavior of denta adhesives: a nanoindentation study. Dent Mater 25: 13-19.

25. Tam LE, Khoshand S, Pilliar RM (2001) Fracture resistance of dentin-composite interfaces using different adhesive resin layers. J Dent 29: 217-225.

26. Van Landuyt KL, Snauwaert J, De Munck J, Peumans M, Yoshida Y, et al (2007) Systematic review of the chemical composition of contemporary dental adhesives. Biomaterials 28: 3757-3785. 